\title{
Single Crystal Electrochemistry as an In-Situ Analytical Characterization Tool
}

Víctor Climent and Juan Feliu

Instituto Universitario de Electroquímica, Universidad de Alicante, Carretera de San Vicente del Raspeig s/n, E-03690, San Vicente del Raspeig, Alicante, Spain

\section{Abstract}

The electrochemical behaviour of platinum single crystal surfaces can be taken as a model response for the interpretation of the activity of heterogeneous electrodes. The cyclic voltammogram of a given platinum electrode can be considered a fingerprint characteristic of the distribution of sites on its surface. We start this review by giving some simple mathematical description of the voltammetric response in the presence of adsorption processes. Then, the voltammogram of platinum basal planes is described, followed by the description of the response of stepped surfaces. The voltammogram of polycrystalline materials can be understood as a composition of the response of the different basal contributions. Further resolution in the discrimination of different surface sites can be achieved with the aid of surface modification using adatoms such as bismuth or germanium. The application of these ideas will be exemplified with the consideration of real catalysts composed of platinum nanoparticles with preferential shapes.

\section{Keywords:}

Platinum single crystal electrodes, cyclic voltammetry, adsorption, nanoparticles with preferential shapes.

\section{Introduction:}

The reactivity of solid electrodes, as compared to that of mercury, was an unresolved challenge until the work of many excellent electrochemists such A.N. Frumkin (1), S. Gilman (2), M.W. Breiter (3) and F.G. Will (4), among many others (5). The reader can find some reviews describing how this problem was finally solved (6-8). The starting point taken here is that from the 1970's, in which the characteristic voltammetric fingerprint for polycrystalline platinum, $\mathrm{Pt}($ poly), was reproducible in most laboratories worldwide (9). This fingerprint voltammogram, given in figure 1 , curve $b$, came associated to an excellent reactivity, both for hydrogen evolution and oxidation in acidic solutions, with a $30 \mathrm{mV}$ Tafel slope $(10,11)$, which can be considered that corresponding to a Nernstian process, while results under "dirty" conditions produced Tafel slopes closer to $120 \mathrm{mV}$ (12). The voltammogram shows characteristic reversible peaks at 0.13 and $0.27 \mathrm{~V} \mathrm{RHE}$ attributed to hydrogen adsorption, including a small feature at $0.21 \mathrm{~V}$ RHE only in the positive scan. This hydrogen region is followed by a low current interval at higher potentials, the socalled double layer region, that finally leads to a complex oxidation of the surface, above $0.80 \mathrm{~V}$, before reaching oxygen evolution. This was attributed to the formation of a monolayer of oxide, which is reduced in a quasi-reversible process in a single peak at $0.74 \mathrm{~V}$. 
A polycrystalline material is heterogeneous and contains many crystallites or grains with unmatching crystallographic orientations. In this regard, any platinum wire, foil or deposited layer will be different from any other. In this case, the number of surface atoms per unit area in contact with the solution is unknown. In addition, all the surfaces are covered by impurities from the laboratory atmosphere that should be removed before starting any meaningful electrochemical experiment. For this purpose, an electrochemical activation procedure, cycling between hydrogen and oxygen evolution in clean sulphuric acid solutions, was accepted as standard (4). After this electrode pre-treatment, all the different samples led to similar voltammetric responses, having the characteristics described above. We can consider that this is the zeroth level approximation for those working with platinum electrodes: start by reproducing this classical result. We can try to be more precise and study the voltammetry of a platinum single crystal bead, obtained after melting a pure (4N) Pt wire. If prepared carefully, the bead reveals the existence of flat areas, regularly distributed on its spherical surface. The distribution of those facets allows to check if the bead is a single crystal. The voltammetry of this bead in the low potential region (figure 1, curve a), recorded after flame annealing, following the procedure given by J. Claviler in 1980 (13-15), is slightly different to that previously described. However, it still features the same main states at 0.13 and $0.27 \mathrm{~V} \mathrm{RHE}$, with small changes in the peak heights (the peak at $0.13 \mathrm{~V}$ is smaller and that at $0.27 \mathrm{~V}$ is higher). Also, the peaks are sharper and the state at $0.2 \mathrm{~V} \mathrm{RHE}$ is not observed. In addition, reversible adsorption states rise at $0.37 \mathrm{~V}$ and a sharp feature is identified at $0.45 \mathrm{~V}$. It is important to remark that this Pt bead also exhibits a $30 \mathrm{mV}$ Tafel slope for hydrogen evolution/oxidation, the same reactivity of the activated samples, and also leads to a voltammogram comparable to that of the activated samples after a few (usually 10) excursions to high potentials, close to oxygen evolution, in a process in which the surface area remains essentially constant. Later, it was documented that the cycling activation process, albeit cleaning the platinum samples, also disorders the surface, at atomic level (16-20). We consider that this type of bead electrodes, cleaned by flame annealing, constitute a reproducible state of the Pt(poly) electrodes, having polyoriented surfaces in which all sites are regularly distributed.

In this contribution we are trying to analyse the voltammogram of the Pt(poly) by using the information derived from model single crystal electrodes, separating the different contributions that appear in the low potential range, in a similar way as the separation by anion and cations groups used in qualitative inorganic analysis. The aim will be to get information about the different population of sites of different symmetry on polycrystalline samples, including platinum nanoparticles. Some comments will be addressed to the interpretation of the voltammograms of single crystal platinum electrodes, a subject that was intensively investigated by J. Clavilier $(13,14,21)$, C.N. Reilley (22-27) and many others (7).

Since the initial studies using single crystal electrodes $(7,13,14,21)$, it became immediately clear that the blank cyclic voltammograms are, in general, extremely sensitive to the crystallographic structure of the surface of the electrode and to the chemical composition of the solution. This is characteristic of electrochemical responses involving adsorption processes, since the energies of adsorption and the interactions between adsorbed species are very sensitive to the arrangement of atoms around the adsorption site. As in the Pt(poly), triangularshaped peaks are obtained at different potentials that are linked to the Gibbs free energy of adsorption, as will be described below. Secondly, the area under a voltammetric peak is related with the charge involved in the adsorption process: 


$$
q=\int_{E_{1}}^{E_{2}} \frac{j}{v} d E
$$

The charge will be related, according to Faraday's laws, to the amount of adsorbed species.

The chapter will be organised as follows: initially, a brief mathematical description of the voltammetric response in the presence of adsorption processes will be given. Then, the voltammogram of platinum single crystal electrodes will be taken as a model to understand the relationship between surface structure and the voltammetric response for platinum surfaces. Finally, the voltammetric results obtained for complex Pt(poly) surfaces and platinum nanoparticles will be described to illustrate the application of these concepts to the characterization of real catalysts. In this latter case, nanoparticles with preferential shapes will demonstrate the correlation between shape and voltammetric response.

\section{Voltammetric response in the presence of adsorption processes.}

When an electroactive species in solution can be adsorbed on the surface of the electrode following an electrosorption process such as:

$\mathrm{M}^{+}+\mathrm{e} \square \mathrm{M}$

Or

$\mathrm{X}-\square+\mathrm{e}$

the amount of adsorbed species is described in terms of the surface concentration, $\Gamma$ (moles per unit of area), or in terms of the fractional coverage

$$
\theta=\frac{\Gamma}{\Gamma_{m}}
$$

where $\Gamma_{m}$ is the maximum amount of adsorbed species. For electrosorption processes such as those described above, both $\Gamma$ and $\theta$ are functions of the electrode potential. For a given solution composition and fixed values of pressure and temperature, the relationship between $\theta$ or $\Gamma$ on the electrode potential is called an electrosorption isotherm $(\theta=\theta(E))$. For a Langmurian behaviour, the most general way of expressing the adsorption isotherm would be: (28)

$$
\frac{\theta}{1-\theta}=c \exp \left(-\frac{\Delta G^{0}}{R T}\right) \exp \left( \pm \frac{F E}{R T}\right)
$$

Where the sign of the second exponential term depends on whether the electrosorption is an oxidation or a reduction, $c$ is the concentration of the adsorbate in the solution and all the other symbols have their usual meaning. In general, the energy of adsorption will be a function of the coverage, $\Delta G^{0}=f(\theta)$, a result of lateral interactions between adsorbed species.

To derive the shape of the voltammogram from the isotherm above, we need to consider the relationship between the coverage and the charge involved, which, according to Faraday laws, is given by:

$$
q= \pm F \Gamma_{m} \theta
$$

In consequence, the current is given by: 


$$
j= \pm F \Gamma_{m} \frac{d \theta}{d t}= \pm F \Gamma_{m} \frac{d \theta}{d E} \frac{d E}{d t}= \pm F \Gamma_{m} \frac{d \theta}{d E} v
$$

because the electrode potential is varied linearly with time at a sweep rate $v$. The $d \theta / d E$ term can be derived from a suitable adsorption isotherm. One interesting result becomes evident from this equation: the voltammetric current depends linearly on the scan rate, a characteristic of adsorption processes (29).

Two simple situations are most commonly considered in the literature. First, when $\Delta G^{0}$ is constant, the generalised isotherm above reduces to the well-known Langmuir isotherm. In this case, taking the derivative $d \theta / d E$ from the isotherm is straightforward. It is easy to demonstrate that the voltammogram in this case provides symmetric peaks, where the position of the peak is linked to the energy of adsorption (that, in this case, is independent of coverage), the height and area under the peak being related with the maximum coverage, $\Gamma_{m}(30-32)$. The width of the peak at half height has a constant value of $90 \mathrm{mV}(31,32)$ (more generally, it would be $90 / n$, where $n$ is the number of electrons exchanged). The next step is to consider a linear variation of the energy of adsorption with the coverage, $\Delta G=\Delta G_{\theta=0}+r \theta$, leading to the Frumkin isotherm:

$$
\frac{\theta}{1-\theta}=c \exp \left(-\frac{\Delta G_{\theta=0}^{0}}{R T}\right) \exp \left(\frac{ \pm F E-r \theta}{R T}\right)
$$

Using this equation, it is possible to demonstrate that symmetric peaks are still obtained, centred around the value of $\theta=0.5$ with different width at half height, depending on the value of the lateral interaction parameter, $r$. Positive values of $r$ (repulsion) give broader peaks while negative values of $r$ (attraction) give narrower peaks (31-33). As before, the position of the peak is related with the energy of adsorption and the area under the peak allows a determination of the amount of adsorbed species.

Figure 2 illustrates the cyclic voltammogram for an electrosorption process of an anion following the isotherms described above. When different species are adsorbed on different sites or on different potential regions, the resulting voltammogram will contain one peak for each process. Single peaks can be also due to competitive adsorption processes (32) and this complicates the quantitative analysis of peak shapes. In this case, the charge under the peak still remains proportional to the number of surface sites, although a suitable calibration is required.

Another factor to consider is the existence of a pure capacitive current overlapped with the adsorption processes. Capacitive currents are typically smaller than those associated with adsorption processes, but they are not negligible. When an independent measurement of the differential capacitance values is lacking, it is customary to approximate the capacity current as a constant, extrapolated from the so-called double layer region of the voltammogram (e.g. between 0.6 and $0.8 \mathrm{~V}$ in figure 1 ).

\section{Electrochemistry with platinum single crystal electrodes}

To rationalize the reactivity of complex catalytic materials (such as nanoparticles or polycrystalline materials), the work with single crystal electrodes is of fundamental value. As will be described in this section, the voltammetry of single crystal surfaces in the blank supporting electrolyte provides valuable information about the structure of the electrode that can later be used to characterize more complex surfaces. 


\subsection{Some notions of surface crystallography}

Monooriented single crystal surfaces are obtained by cutting a single crystal with an ideally atomically flat surface (a mathematical plane). For materials that crystalize in the face centred cubic crystalline network, the three basal planes defined by the Miller Indices (111), (100) and (110) correspond to the surfaces with the simplest structure. To describe the structure of surfaces with higher Miller indices it is very useful to employ the stereographic triangle $(6,34$, $35)$, which is the mathematical way to represent a three dimensional structure in two dimensions. The basal planes are situated at the corners of the stereographic triangle. The edges that join two basal planes contain stepped surfaces formed by terraces of one symmetry and steps of the second symmetry. For platinum, the line that separates the $\mathrm{Pt}(111)$ and $\mathrm{Pt}(100)$ surfaces contains stepped surfaces. Those surfaces closer to the Pt(111) corner are formed by $\mathrm{Pt}(111)$ terraces separated by monoatomic $\mathrm{Pt}(100)$ steps, while the surfaces closer to the $\mathrm{Pt}(100)$ corner contain Pt(100) terraces separated by monoatomic Pt(111) steps. Those surfaces can be designated as $\mathrm{Pt}(\mathrm{S})[\mathrm{n}(111) \times(100)]$ and $\mathrm{Pt}(\mathrm{S})[\mathrm{n}(100) \times(111)]$, respectively (36). A particular orientation is $\mathrm{Pt}(311)$, the turning point, in which both series of surfaces coincide. Similar situation also holds for the other two edges of the stereographic triangle. The surfaces lying in the centre of the stereographic triangle contain sites with the symmetries of the three basal planes. Figure 3 summarizes some of these relationships, giving also the relation between the structure of the surface and the Miller indices $(34,37,38)$

The hard sphere models of the surfaces, as shown in figure 3, provide valuable relationships between the structure and the Miller indices. The most important elements of this model are the unit cell, its dimensions and the number of atoms of each type it contains. For instance, for the (111) surface, the unit cell contains only one atom. From the geometries indicated in the figure, it is possible to calculate the atomic density of the surface (surface atoms per unit area):

$$
N=\frac{1}{S}=\frac{2}{\sqrt{3} d^{2}}
$$

Where $S$ is the area of the unit cell and $d$ is the atomic diameter. From the point of view of an electrochemist, even more important than the atomic density is the charge corresponding to one electron per atom on the surface. Continuing with the $\mathrm{Pt}(111)$ surface, as example:

$$
q_{111}=\frac{e}{S}=\frac{2 e}{\sqrt{3} d^{2}}=240 \mu \mathrm{Ccm}^{-2}
$$

Where $e$ is the unit charge. Similar relationships can be obtained for the other basal planes, as summarized in table 1. Unlike Pt(poly), on single crystal electrodes, a measure of the charge is related to the number of surface atoms.

In the case of stepped surfaces, the dimensions of the unit cell depend on the number of atomic rows on the terrace, $n$. The dimension of the unit cell for three selected families of stepped surfaces are indicated in figure 3 . In this case, not all the atoms in the unit cell are equivalent since they will have different electronic properties as they are farther or closer to the step. Usually, the atoms can be classified as terrace and step atoms. As before, more important than the number of atoms is the charge corresponding to the exchange of one electron per terrace atom or one electron per step atom. For all the cases drawn in figure 3 the unit cell contains only one step atom. Therefore, the charge corresponding to steps will be $q^{\text {step }}=e / S$. The resulting expressions after substituting the particular dimensions of each unit cell are summarized in table 1. The number of terrace atoms depends on the geometry of the stepped surface. For instance, 
for the surfaces with (111) terrace and (110) step, the step is wider and there are $n-2$ terrace atoms in the unit cell.

$$
\frac{q_{\text {terr }}^{111}}{\cos (\alpha)}=\frac{(n-2) e}{S}=\frac{\left(n-\frac{2}{3}+\frac{2}{3}-2\right) e}{\frac{\sqrt{3}}{2} d^{2}\left(n-\frac{2}{3}\right)}=\frac{e}{\frac{\sqrt{3}}{2} d^{2}}\left(1-\frac{4}{3} \frac{1}{\left(n-\frac{2}{3}\right)}\right)=q_{P t(111)}-\frac{4}{3} \frac{q_{P t(111)}}{n-\frac{2}{3}}
$$

Similar expressions are obtained for the other stepped surfaces. In these expressions, the term $\cos (\alpha)$ accounts for the projection of the area of the unit cell on the plane of the terrace (the length of the unit cell is measured on the plane of the terrace but the experimental area is measured on the plane of the stepped surface). The important conclusion is that not only the number, but the type of surface atoms per unit area, are known for single crystal electrodes.

\subsection{Cyclic voltammetry of platinum single crystal electrodes.}

Figure 4 shows the voltammograms for the three basal planes in perchloric and sulfuric acid solutions. The first observation is that the voltammogram is very sensitive to both the crystallographic orientation and the composition of the solution. In all cases, the voltammogram is composed by a number of peaks, some broader some narrower, but in all cases symmetric through the $\mathrm{x}$-axis. This indicates that those adsorption processes are fast in the time scale of the experiment. Perchloric acid is usually selected as supporting electrolyte in fundamental studies, because perchlorate anion does not adsorb specifically on the platinum surface. The processes registered in this case are hydrogen adsorption, in the low potential region and hydroxyl adsorption at higher potentials. It is clear that adsorption energies depend markedly on the symmetry of the surface, since the peak positions vary among the different surfaces.

The voltammogram in the presence of sulfuric acid clearly evidences the sensitivity of the technique to the composition of the solution. Sulphate anions adsorb specifically on the surface of platinum and the energy of adsorption (also the geometry of adsorption) depends on the symmetry of the surface. The result is that, for all cases, the hydroxyl adsorption states are replaced by sulphate adsorption that is shifted to negative potentials, resulting in a "compression" of the voltammetric profile into a narrower range of potentials. Sulphate adsorption on $\mathrm{Pt}(111)$ starts around $0.33 \mathrm{~V}$. At first, the adsorption is disordered but around 0.45 $V$ a phase transition takes place, resulting in the formation of an ordered adlayer with $(\sqrt{3} \times \sqrt{7})$ structure, as has been evidenced by $\operatorname{STM}(39,40)$. It is important to note that the voltammograms in $\mathrm{HClO}_{4}$ and $\mathrm{H}_{2} \mathrm{SO}_{4}$ overlap perfectly at potentials below $0.33 \mathrm{~V}$, indicating that anion adsorption does not participate in these low potential adsorption states. For $\mathrm{Pt}(100)$, the broad adsorption states extending up to $0.7 \mathrm{~V}$ in $\mathrm{HClO}_{4}$ are compressed in a narrower peak below $0.45 \mathrm{~V}$. In this case, hydrogen desorption and sulphate adsorption are coupled in a single peak. It could be said that sulphate adsorption forces the desorption of hydrogen at potentials where, otherwise, hydrogen would still be stable in the adsorbed state. A similar situation happens with $\mathrm{Pt}(110)$, with most of the adsorption state being compressed in a single peak centred at $0.14 \mathrm{~V}$. In both cases, the voltammetric profiles in perchloric and sulphuric acid overlap at low potentials, were the current is only due to hydrogen adsorption.

A first comparison between the two electrolytes reveals that sulphuric acid solutions are more convenient for characterization purposes, because the voltammetric peaks are better defined. This is general for other electrolytes containing anions that adsorb specifically, but sulphuric acid is preferred to other acidic solutions for several reasons, related with solution cleanliness (e.g. in comparison to phosphoric acid, which was the preferred electrolyte for the fuel cells and has 
similar adsorption properties) or stability (e.g. chlorides adsorb more strongly on the surface, but platinum dissolution/corrosion can be a problem for the integrity of the electrodes at high potentials).

One important conclusion from what has been described above is that, in general, it is very risky to assign one voltammetric peak to a single process since most often more than one process is coupled under the same peak. Cyclic voltammetry alone cannot separate the different processes in those cases. One technique that comes to our rescue in those cases is the charge displacement (41-43). This technique consists in the introduction of a displacing agent that adsorb very strongly on the surface of the electrode, displacing everything that was initially present at the interphase. The current that flows due to the displacement reaction is monitored during the whole process. In this way, the sign and magnitude of the displaced charge gives information about the nature of the displaced species. The best displacing agent for platinum is carbon monoxide because it adsorb strongly, its adsorption does not involve charge, it is easily introduced in the cell as a gas, and, the best of all, it can be easily removed from the solution by bubbling argon and, then, the adsorbed layer can be stripped at reasonably low potentials, recovering the initial electrode surface. If the displacing experiment is performed while holding the potential in the hydrogen region, positive charges are displaced, as expected, according to:

$\mathrm{Pt}-\mathrm{H}+\mathrm{CO} \square \mathrm{Pt}-\mathrm{CO}+\mathrm{H}^{+}+\mathrm{e}$

At the onset of hydrogen evolution, the following charges are obtained for the three basal planes: $160 \mu \mathrm{C} / \mathrm{cm}^{2}$ for $\mathrm{Pt}(111)(41,44,45), 150 \mu \mathrm{C} / \mathrm{cm}^{2}$ for $\mathrm{Pt}(110)(41,45)$ and $200 \mu \mathrm{C} / \mathrm{cm}^{2}$ for $\mathrm{Pt}(100)$ (45). These values give a measure of the maximum amount of hydrogen adsorbed on each surface. For Pt(110) and $\mathrm{Pt}(100)$, they are close to the value calculated for one electron for each atom on the surface (table 1 ). For Pt(111) only $2 / 3$ of the surface appears to be covered by hydrogen before the onset of hydrogen evolution. In all cases, starting at this potential with the surface covered by hydrogen, sweeping the potential to positive values causes the desorption of hydrogen and the adsorption of the anion. In the high potential region, anions start to be replaced by oxides, but this potential region is typically avoided when working with single crystals since it causes the disordering of the surface.

In this respect, if the displacement is performed at high potential, where the surface is covered by anions, negative charges are obtained:

$\mathrm{Pt}-\mathrm{A}+\mathrm{CO}+\mathrm{e} \square \mathrm{Pt}-\mathrm{CO}+\mathrm{A}^{-}$

Once the voltammetry of platinum single crystals is well understood, it is also possible to understand the voltammetry of polycrystalline materials. In this way, the peak at 0.13 in the voltammograms of figure 1 can be assigned to hydrogen and anion adsorption/desorption on (110) facets. The contribution of (111) facets would be a rather flat background in this region. However, it is clear that the state at $0.27 \mathrm{~V}$ on Pt(poly) does not appear on the basal planes (compare figures 1 and 4). Figure 5 shows that this state dominates in the stepped surfaces containing (100) step sites separating (111) terraces (46). Also, a similar state appears when stepped surfaces with (100) terraces are under scope (47). The contribution of long ordered $(100)$ terraces $(0.37 \mathrm{~V}(47))$ appears as a shoulder in the voltammogram of the polycrystalline material. Therefore, to investigate the effect of long-range order in the voltammetric response it is necessary to study the response of stepped surfaces.

Figure 5 shows the voltammograms obtained with several stepped surfaces formed by (111) terraces and either (110) or (100) steps. A comparison of the voltammogram of the 
polycrystaline material with the stepped surfaces is given in figure 5D. From Figure $5 \mathrm{~A}$, the introduction of the (110) steps causes the growth in the voltammogram of a peak at $0.13 \mathrm{~V}$, that becomes larger as the step density increases. When the symmetry of the step changes to (100) (figure $5 \mathrm{~B}$ ), the introduction of the step causes similar changes in the voltammogram, but the position of the peak is shifted now to $0.24 \mathrm{~V}$. Those peaks corresponding to the contribution of the steps have been assigned to the adsorption of one hydrogen atom per platinum atom on the step (48). It is noteworthy to stress that the position of the peak shifts to slightly higher values when the terraces are shorter. Also, the cycling of the potential into the oxide region for the stepped surfaces leads to less intense, broader peaks and the development of new contributions, as a consequence of the surface disorder, mimicking the behaviour observed with Pt(poly).

The relationships from the hard sphere model summarized in table 1 are useful here to analyse the different charge contributions in the voltammogram of stepped surfaces. In the case of $\mathrm{Pt}(\mathrm{S})[n(111) \times(110)]$ stepped surfaces, the separation of the charge contribution from the step is quite straightforward considering a straight base line (see figure 7B). The charge values obtained in this way can be plotted as a function of the step density, resulting a straight line that can be taken as a calibration curve that allows to calculate the step density of an unknown surface from the integration of the $(110)$ peak $(49,50)$. For $n(111) \times(100)$ surfaces, anion adsorption on the steps complicates the interpretation of the charge (51). Also, the base line for the integration is more ambiguous. Still, independently of the interpretation about the species involved, a calibration curve plotting charge and step densities can be obtained in this case, allowing the estimation of the density of (100) step sites for any heterogenous platinum surface (46).

For the surfaces with (100) terrace and (111) step (figure 5C) we can see a contribution around $0.38 \mathrm{~V}$ corresponding to the adsorption on the $(100)$ terrace, growing as the length of the terrace increases. The contribution from the (111) step can be identified around $0.08 \mathrm{~V}$, while the peak at $0.28 \mathrm{~V}$ is assigned to the adsorption on (100) places next to the step. This assignment comes from the coincidence of the peak position in $\operatorname{Pt}(S)[n(111) \times(100)]$ and in $\operatorname{Pt}(S)[n(100) \times(111)]$ stepped surfaces (52).

\section{Calculation of facet contribution of any polycrystalline platinum surface}

We have seen that cyclic voltammetry of platinum electrodes in blank electrolyte solutions provide a response sufficiently sensitive to obtain a rather accurate description of the structure of the surface. This is based on the hydrogen and anion adsorption reactions that provide a number of peaks with well differentiated position, corresponding to (100) and (110) site contributions. We have also seen that well-ordered (100) terraces give a distinctive voltammetric contribution at slightly higher potentials than that of the isolated (100) sites. Finally, (111) widely ordered terraces can be identified in sulphuric acid solution from the sulphate adsorption states, which develop at relatively high potentials. For (111) terrace sites, hydrogen adsorption does not exhibit any peak, i.e. even identifying the presence of these sites in the voltammogram by the presence of the sharp peak at $0.45 \mathrm{~V}$ (see figure 1a), the contribution of this orientation in the hydrogen region cannot be distinguished from a horizontal base line. In this respect, to quantify the presence of the (111) sites on Pt(poly) it is necessary a specific surface site probe other than hydrogen/anion adsorption. This is equivalent to the direct probes used in qualitative inorganic analysis, which ion determination avoiding any separation in groups from a complex solution. 


\subsection{Adatom modified surfaces as a tool to separate different surface contributions.}

Several elements of groups IVA, VA and VIA of the periodic table can be irreversibly adsorbed on platinum, just by exposing the electrode to solutions that contains the element in a suitable ionic form. Those elements are Bi $(53,54)$, Ge $(55), \mathrm{As}(56,57)$, Sb $(56,58)$, Se $(59)$ and Te $(60)$. The term "irreversible" means here that the element remains adsorbed even in the absence of the corresponding ion in the solution (there is no equilibrium between surface and solution species). Moreover, the irreversibly adsorbed adatoms give an oxidation/reduction process with well distinctive voltammetric peaks (61). For instance, for $\mathrm{Bi}$ on $\mathrm{Pt}(111)$ a surface redox process appears at $0.62 \mathrm{~V} \mathrm{RHE}$, in the so-called double layer region, without interference with other processes in the blank electrolyte. Indeed, on $\mathrm{Pt}(100)$ or $\mathrm{Pt}(110)$ the Bi redox peak appears at potentials well above $0.8 \mathrm{~V}$.

Thus, the peak potential for this redox process is sensitive to the symmetry of the site where the adatom is adsorbed and the charge under the peak is a measure of the number of (111) sites covered by the adatom. By covering the whole surface with Bi adatoms (attaining the maximum surface blockage) the charge under the adatom peak at $0.62 \mathrm{~V} \mathrm{RHE}$ is also a measure of the number of sites of (111) symmetry. The validation of this method was done using two series of stepped surfaces containing (111) terraces of well-known length separated by monoatomic steps of (100) and (110) site symmetry (62). For these surfaces, the charge of (111) sites on the terrace is given in table 1. By plotting the charge corresponding to the bismuth adatoms as a function of the nominal charge of terrace sites, a straight line is obtained that gives the stoichiometry of the reaction (62):

$q_{B i}=(0.64 \pm 0.02) q_{(111)}^{t-1}$

Such plot is shown in figure $6 \mathrm{~B}$. This line can be taken as a calibration curve that relates the charge corresponding to (111) sites with the experimental value of the bismuth charge. The resulting slope agrees with a situation where each Bi blocks 3 platinum atoms on the closepacked (111) terraces $\left(\theta_{\max }=0.33\right)$ and exchange 2 electrons. Anyway, the calibration plot is independent of any assumption/interpretation on the surface redox reaction stoichiometry. Similar experiments/conclusions can be performed by using Te as surface probe sensitive to (111) domain sites with good agreement, despite a different surface redox reaction (62).

Similarly, germanium on Pt(100) gives a distinctive peak at $0.55 \mathrm{~V}$, well separated from the peaks corresponding to the other adsorption sites. Again, the method is calibrated using stepped surfaces with (100) terraces (62). As before, the plot of the germanium charge as a function of the charge corresponding to (100) terrace atoms gives a straight line (figure 6D) according to (62):

$q_{G e}=(0.56 \pm 0.03) q_{(100)}^{t}$

In this case, the stoichiometry agrees with a Ge atom blocking 4 platinum atoms $\left(\theta_{\max }=0.25\right)$ and exchanging 2 electrons.

In the following section, it will be shown how these methods have been successfully applied to the characterization of the surface properties of nanoparticles.

\subsection{Fit to multiple peaks as a mathematical tool to separate different contributions.}

As explained above, to obtain a quantification of the different facets on the surface of a polycrystalline material from the hydrogen adsorption region, some deconvolution of the different peaks becomes necessary. It has also been discussed above that the shape of the 
voltammetric peaks can be understood considering the Frumkin isotherm (or more generally a generalised isotherm where the adsorption Gibbs free energy varies with the coverage). The response of a heterogeneous surface will correspond to the weighted addition of the different facets that form it, since every facet will respond independently to the voltammetric scan. Then, the response of a complex surface can be separated into several peaks from different isotherms $(63,64)$. However, even in the simplest case of a Frumkin isotherm, the mathematical equation for calculating the current as a function of potential is not explicit and the fit of experimental data using several Frumkin isotherms by a least square minimum method is not straightforward. To avoid this complication, the use of Lorentzian and Gaussian functions has been proposed, and it was demonstrated that best results were obtained with Lorentzian-shaped peaks (62). Still, due to the overlap of the peaks, there is some ambiguity in their separation. Particularly, the hydrogen adsorption on (111) facets gives a rather flat background overlapped with the (110) and (100) responses. The bismuth adsorption strategy described above provides a way to solve this ambiguity and the following procedure has been proposed to achieve a complete separation of the different adsorption states on a polycrystalline material (62): i) first, the fraction of (111) sites is determined using bismuth as a surface probe; ii) the (111) contribution is subtracted from the hydrogen adsorption region using the scaled voltammogram of a (111) containing platinum surface. It has been argued that, for this subtraction, it is better to use a stepped Pt(554) surface instead of a Pt(111), since the former represents better the lack of long range order on the polycrystalline material; the double layer (capacitive) contribution is also subtracted using as constant value the current in the double layer region; iii) the corrected current is used to fit a suitable number of Lorentzian peaks (five or six) that allows separation of the different contributions; iv) finally, the contribution from different (100) sites can be added and compared with the result obtained using germanium as a surface probe. Consistent results are obtained with both methodologies. Figure 7 exemplifies the steps indicated above for the same polyoriented bead electrode given in figure 1.

\subsection{Application to real catalysts: platinum nanoparticles with preferential shapes:}

A nanoparticle dispersion is the preferred form of an electrocatalysts for its practical applications, in order to maximize the specific surface of the active material in relation to its mass. This is particularly important for precious metals such as Pt. One of the main conclusions from the previous pages is that the surface structure is of paramount importance to define the reactivity of a given electrode material. Therefore, controlling the surface structure of the nanoparticles is necessary to achieve the best performance in structure sensitive reactions. Important steps have been given in this direction by developing synthetic methodologies giving nanoparticles with preferential shapes $(62,65-70)$.

Figure 8 shows the voltammetric response of different platinum nanoparticles synthesised by different methods that produce different preferential shapes. The TEM images demonstrate the existence of preferential faceting on the surface of the nanoparticles. Once cleaned, the nanoparticles produced with the micellar method without any modification give $4 \mathrm{~nm}$ spherical nanoparticles. The symmetrical cyclic voltammogram does not show the existence of any large domain contribution and, therefore, these nanoparticles behave as any normal polycrystalline platinum. The nanoparticles synthesised using the polyacrylate method, using $\mathrm{K}_{2} \mathrm{PtCl}_{4}$ as precursor and $\mathrm{H}_{2}$ as reducing agent, produce $10 \mathrm{~nm}$ cubic nanoparticles enclosed in $\{100\}$ facets (62). Clear differences are observed in the voltammogram in this case. Adsorption peaks are sharper, with the peak corresponding to (100) short sites $(0.27 \mathrm{~V})$ being higher than the (110) peak $(0.13 \mathrm{~V})$. However, the most important characteristic of this voltammogram is the relatively 
large voltammetric contribution around $0.38 \mathrm{~V}$, that corresponds to large (100) domains, as described above. The contribution around $0.51 \mathrm{~V}$ can be attributed to the existence of some small domains with extended (111) symmetry.

When the method of synthesis is modified by using $\mathrm{H}_{2} \mathrm{PtCl}_{6}$ (instead of $\mathrm{K}_{2} \mathrm{PtCl}_{4}$ ) as precursor, the voltammetric response significantly changes (62). The main difference with the voltammogram for cubic nanoparticles is observed in the relative height of the hydrogen peaks at 0.13 and 0.27 $\mathrm{V}$. Now, the (110) peak at $0.13 \mathrm{~V}$ is higher than the (100) peak at $0.27 \mathrm{~V}$, while the opposite trend is observed for the cubic nanoparticles. Also, the contribution at $0.51 \mathrm{~V}$ corresponding to relatively large (111) terraces increases. Those voltammetric observations are in agreement with the TEM images that reveal nanoparticle shapes with truncated tetrahedral and octahedral shapes. Also, the characterization using bismuth and germanium adatoms agree with the trends just described. The truncated tetrahedral and octahedral nanoparticles show a larger bismuth peak, demonstrating the existence of a large number of (111) sites. On the other hand, the cubic nanoparticles give the largest germanium peak, characteristic of (100) domains. The spherical nanoparticles produce negligible bismuth and germanium peaks demonstrating the lack of ordered domains on these nanoparticles.

The polyacrylate method of synthesis can be refined by reducing the purging time with $\mathrm{Ar}$, therefore allowing the existence of small amount of oxygen in the solution during the synthesis (71). This leads to the formation of tetrahedral and octahedral nanoparticles. The corresponding voltammogram is characterised by the almost complete absence of adsorption states around 0.37 that could be attributed to $(100)$ relatively large domains and the significant decrease of the peak at $0.27 \mathrm{~V}$ corresponding to (100) defects. Also, a clearly discernible contribution around $0.51 \mathrm{~V}$ signals the presence of small (111) domains.

Interesting results have also been obtained with a modification of the micellar method that include the addition of large concentration of mineral acids during the synthesis. Such procedure produces cubic nanoparticles $(67,69,70)$. The best results are obtained with $15 \% \mathrm{HCl}$ using $\mathrm{K}_{2} \mathrm{PtCl}_{4}$ as platinum precursor (69). More recently, synthesis of octahedral nanoparticles with remarkably well defined shapes was obtained using sodium citrate, ascorbic acid and a careful control of the reaction rate (72).

The specific reactivity of the nanoparticles has been tested for different reactions such as formic acid oxidation (73), ammonia oxidation $(67,70,74)$ and nitrate reduction $(75,76)$. Perhaps the most striking result was obtained for ammonia oxidation, a reaction extremely sensitive to the presence of (100) domains. The use of single crystal showed that the reactivity of surfaces having (111) or (110) symmetry is almost negligible for this reaction. In this way, the use of good quality cubic nanoparticles leads to an increase of peak current for this reaction by a factor of 5 with respect to any other sample of nanoparticles used, which have indeed (100) sites. In general, (100) sites are the most active for reactions that involve $\mathrm{NH}_{\mathrm{x}}$ adsorbed species, like ammonia oxidation (74) and nitrite reduction (77).

\section{Conclusions}

In the previous pages we have demonstrated the strong sensitivity of the voltammetric response of platinum electrodes to the crystallographic structure of their surface. In this way, the voltammetry becomes an easy and inexpensive surface characterization method with a remarkable sensitivity. Surface concentrations of less than $1 \%$ can be easily detected. This result can be extended to other metals, since most adsorption processes exhibit similar sensitivities. Metals such as gold $(78,79)$, palladium (80-82) and rhodium (83-85) have been characterised in 
a similar way. When the adsorption processes occurring in the supporting electrolyte are not clear enough, the method can be extended with the use of additional surface modifiers. In the case of platinum, irreversible adsorption of adatoms of $\mathrm{Bi}$, Te or Ge have been successfully applied with this purpose. For gold, underpotential deposition of lead has also been used to characterise complex surfaces with the same principles as described in this review $(78,79)$.

\section{Acknowledgment}

This work has been financially supported by the MINECO (Spain) project No. CTQ2016-76221-P. Figures have been prepared using the free software matplotlib (86).

\section{References}

1. Frumkin AN, Petrii OA. 1975. Potentials of zero total charge and zero free charge of platinum group metals. Electrochimica Acta 20: 347-59

2. Gilman S. 1965. Modification of the surface area of platinum electrodes by the application of single pulses. Journal of Electroanalytical Chemistry (1959) 9: 276-81

3. Breiter MW. 1969. Electrochemical processes in fuel cells. [New York]: Springer-Verlag New York. xi, 274 p. pp.

4. Will FG. 1965. Hydrogen adsorption on platinum single crystal electrodes. I. Isotherms and heats of adsorption. Journal of the Electrochemical Society 112: 451-55

5. Llopis JF, Colom F. 1976. Platinum. In Encyclopedia of Electrochemistry of the Elements, ed. AJ Bard, pp. 170-221. New York and Basel: Marcel Dekker, Inc.

6. Hamelin A. 1985. Double layer properties at sp and sd Metal Single-Crystal electrodes. In Modern Aspects of Electrochemistry, ed. BE Conway, RE White, JOM Bockris, pp. 1101. New York: Plenum

7. Climent V, Feliu JM. 2011. Thirty years of platinum single crystal electrochemistry. Journal of Solid State Electrochemistry 15: 1297-315

8. Clavilier J, Rodes A, Elachi K, Zamakhchari MA. 1991. Electrochemistry at platinum single-crystal surfaces in acidic media - hydrogen and oxygen-adsorption. Journal De Chimie Physique Et De Physico-Chimie Biologique 88: 1291-337

9. Conway BE, Angerstein-Kozlowska. H, Sharp WBA, Criddle EE. 1973. Ultrapurification of water for electrochemical and surface chemical work by catalytic pyrodistillation. Analytical Chemistry 45: 1331-36

10. Bockris JOM, Ammar IA, Huq AKMS. 1957. The Mechanism of the Hydrogen Evolution Reaction on Platinum, Silver and Tungsten surfaces in Acid Solutions. The Journal of Physical Chemistry 61: 879-86

11. Bockris JOM, Koch DFA. 1961. Comparative rates of the electrolytic evolution of hydrogen and deuterium on iron, tungsten and platinum. The Journal of Physical Chemistry 65: 1941-48

12. Bockris JOM, Khan SUM. 1993. Surface electrochemistry : a molecular level approach. New York ; London: Plenum. xxxii, 1014 p. pp.

13. Clavilier J, Faure R, Guinet G, Durand R. 1980. Preparation of monocrystalline Pt microelectrodes and electrochemical study of the plane surfaces cut in the direction of the $\{111\}$ and $\{110\}$ planes Journal of Electroanalytical Chemistry 107: 205-09

14. Clavilier J. 1980. The role of anion on the electrochemical behaviour of a $\{111\}$ platinum surface; an unusual splitting of the voltammogram in the hydrogen region Journal of Electroanalytical Chemistry 107: 211-16

15. Clavilier J. 1999. Flame-Annealing and Cleaning Technique. In Interfacial Electrochemistry, ed. A Wieckowski, pp. 231-48. New York: Marcel Dekker, Inc. 
16. Motoo S, Furuya N. 1984. Electrochemistry of platinum single crystal surfaces: Part I. Structural change of the Pt (111) surface followed by an electrochemical method. Journal of Electroanalytical Chemistry 172: 339-58

17. Itaya K, Sugawara S, Sashikata K, Furuya N. 1990. In Situ Scanning Tunneling Microscopy of Platinum (111) Surface with the Observation of Monatomic Steps. Journal of Vacuum Science \& Technology a-Vacuum Surfaces and Films 8: 515-19

18. Furuya N, Ichinose M, Shibata M. 1999. Structural changes at the Pt(100) surface with a great number of potential cycles. Journal of Electroanalytical Chemistry 460: 251-53

19. Furuya N, Shibata M. 1999. Structural changes at various Pt single crystal surfaces with potential cycles in acidic and alkaline solutions. Journal of Electroanalytical Chemistry 467: 85-91

20. Jacobse L, Huang Y-F, Koper MTM, Rost MJ. 2018. Correlation of surface site formation to nanoisland growth in the electrochemical roughening of Pt(111). Nature Materials 17: $277-82$

21. Clavilier J, Durand R, Guinet G, Faure R. 1981. Electrochemical adsorption behaviour of $\mathrm{Pt}(100)$ in sulphuric acid solution Journal of Electroanalytical Chemistry 127: 281-87

22. Scortichini CL, Reilley CN. 1982. Surface characterization of Pt electrodes using underpotential deposition of $\mathrm{H}$ and $\mathrm{Cu}$. 1. Pt(100). Journal of Electroanalytical Chemistry 139: 233-45

23. Scortichini CL, Reilley CN. 1982. Surface characterization of Pt electrodes using underpotential deposition of $\mathrm{H}$ and $\mathrm{Cu}$. 2. Pt(110) and Pt(111). Journal of Electroanalytical Chemistry 139: 247-64

24. Scortichini CL, Woodward FE, Reilley CN. 1982. Surface characterization of Pt electrodes using underpotential deposition of $\mathrm{H}$ and $\mathrm{Cu}$. 3. Surface improvement of the flameannealed $\mathrm{Pt}(100)$ and $\mathrm{Pt}(111)$ electrodes via potential cycling. Journal of Electroanalytical Chemistry 139: 265-74

25. Scortichini CL, Reilley CN. 1983. Surface Characterization of Pt Electrodes Using Underpotential Deposition of $\mathrm{H}$ and $\mathrm{Cu}$.4. Surface Structural Dependence of A NonEquilibrium State of Hydrogen Adsorption. Journal of Electroanalytical Chemistry 152: 255-60

26. Scortichini CL, Reilley CN. 1983. Surface Characterization of Pt Electrodes Using Underpotential Deposition of $\mathrm{H}$ and $\mathrm{Cu}$.5. Characterization of Bd Pt Catalyst Surface. Journal of Catalysis 79: 138-46

27. Woodard FE, Scortichini CL, Reilley CN. 1983. Hydrogen Chemisorption and Related Anion Effects on Pt(110) Electrodes. Journal of Electroanalytical Chemistry 151: 109-31

28. Conway BE, Angerstein-Kozlowska H, Dhar HP. 1974. On selection of standard states in adsorption isotherms. Electrochimica Acta 19: 455-60

29. Bard AJ, Faulkner LR. 2001. Electrochemical Methods. Fundamental and Applications. New York: John Wiley \& Sons, Inc.

30. Bockris JOM, Kita H. 1961. Analysis of Galvanostatic Transients and Application to the Iron Electrode Reaction. Journal of the Electrochemical Society 108: 676-85

31. Gileadi E. 1993. Electrode Kinetics for Chemists. New York: VCH Publishers, Inc.

32. Climent V, Feliu JM. 2015. Cyclic Voltammetry. In Reference Module in Chemistry, Molecular Sciences and Chemical Engineering ed. K Wandelt: Elsevier

33. Conway BE, Gileadi E. 1962. Kinetic Theory of pseudo-capacitance and electrode reactions at appreciable surface coverage. Journal of the Chemical Society, Faraday Transactions: 2493-509

34. Climent V, Feliu JM. 2017. Surface Electrochemistry with Pt Single-Crystal Electrodes. In Advances in Electrochemical Science and Engineering: Nanopatterned and NanoparticleModified Electrodes, ed. RC Alkire, PN Bartlett, J Lipkowski, pp. 1-57. Weinheim: WileyVCH Verlag GmbH \& Co. KGaA 
35. Korzeniewski C, Climent V, Feliu J. 2011. Electrochemistry at Platinum Single Crystal Electrodes. In Electroanalytical Chemistry A Series of Advances: Volume 24, pp. 75-170: CRC Press

36. Lang B, Joyner RW, Somorjai GA. 1972. LEED Studies of High Index Crystal Surfaces of Platinum. Surface Science 30: 440

37. Korzeniewski C, Climent V, Feliu JM. 2012. Electrochemistry at Platinum Single Crystal Electrodes. Electroanalytical Chemistry: A Series of Advances, Vol 24 24: 75-169

38. Van Hove MA, Somorjai GA. 1980. A new microfacet notation for high-Miller-index surfaces of cubic materials with terrace, step and kink structures. Surface Science 92: 489-518

39. Braunschweig B, Daum W. 2009. Superstructures and Order/Disorder Transition of Sulfate Adlayers on Pt(111) in Sulfuric Acid Solution. Langmuir 25: 11112-20

40. Funtikov AM, Stimming U, Vogel R. 1997. Anion adsorption from sulfuric acid solutions on Pt(111) single crystal electrodes. Journal of Electroanalytical Chemistry 428: 147-53

41. Clavilier J, Albalat R, Gómez R, Orts JM, Feliu JM, Aldaz A. 1992. Study of the charge displacement at constant potential during $\mathrm{CO}$ adsorption on $\mathrm{Pt}(110)$ and $\mathrm{Pt}(111)$ electrodes in contact with a perchloric acid solution. Journal of Electroanalytical Chemistry 330: 489-97

42. Clavilier J, Albalat R, Gómez R, Orts JM, Feliu JM. 1993. Displacement of adsorbed iodine on platinum single-crystal electrodes by irreversible adsorption of $\mathrm{CO}$ at controlled potential. Journal of Electroanalytical Chemistry 360: 325-35

43. Orts JM, Gómez R, Feliu JM, Aldaz A, Clavilier J. 1994. Potentiostatic charge displacement by exchanging adsorbed species on $\mathrm{Pt}(111)$ electrodes-acidic electrolytes with specific anion adsorption Electrochimica Acta 39: 1519-24

44. Feliu JM, Orts JM, Gómez R, Aldaz A, Clavilier J. 1994. New information on the unusual adsorption states of $\mathrm{Pt}(111)$ in sulphuric acid solutions from potentiostatic adsorbate replacement by CO Journal of Electroanalytical Chemistry 372: 265-68

45. Clavilier J, Orts JM, Gómez R, Feliu JM, Aldaz A. 1994. On the Nature of the Charged Species Displaced by CO Adsorption from Platinum Oriented Electrodes in Sulphuric Acid Solution. ed. BE Conway, G Jerkiewicz, pp. 167-83. Pennington, NJ: The Electrochemical Society, INC.

46. Rodes A, Elachi K, Zamakhchari MA, Clavilier J. 1990. Hydrogen probing of step and terrace sites on $\mathrm{Pt}(\mathrm{S})-[\mathrm{n}(111) \times(100)]$. Journal of Electroanalytical Chemistry 284: 24553

47. Francke R, Climent V, Baltruschat H, Feliu JM. 2008. Electrochemical deposition of copper on stepped platinum surfaces in the 01(1)over-bar zone vicinal to the (100) plane. Journal of Electroanalytical Chemistry 624: 228-40

48. Gómez R, Climent V, Feliu JM, Weaver MJ. 2000. Dependence of the potential of zero charge of stepped platinum (111) electrodes on the oriented step-edge density: Electrochemical implications and comparison with work function behavior. Journal of Physical Chemistry B 104: 597-605

49. Clavilier J, Elachi K, Rodes A. 1989. In situ characterization of the Pt(S)-[n(111) x (111)] electrode surfaces using electrosorbed hydrogen for probing terrace an step sites. Journal of Electroanalytical Chemistry 272: 253-61

50. Clavilier J, Elachi K, Rodes A. 1990. In situ probing of step and terrace sites on Pt(S)n(111)x(111) electrodes. Chemical Physics 141: 1-14

51. Feliu JM, Herrero E, Climent V. 2011. Electrocatalytic Properties of Stepped Surfaces. In Catalysis in Electrochemistry, ed. E Santos, W Schmickler, pp. 127-63. Hoboken: John Wiley \& Sons, Inc.

52. Attard GA, Hazzazi O, Wells PB, Climent V, Herrero E, Feliu JM. 2004. On the global and local values of the potential of zero total charge at well-defined platinum surfaces: 
stepped and adatom modified surfaces. Journal of Electroanalytical Chemistry 568: 32942

53. Clavilier J, Feliu JM, Aldaz A. 1988. An irreversible structure sensitive adsorption step in bismuth underpotential deposition at platinum electrodes. Journal of Electroanalytical Chemistry 243: 419-33

54. Clavilier J, Feliu JM, Fernandez-Vega A, Aldaz A. 1989. Electrochemical-Behavior of Irreversibly Adsorbed Bismuth on Pt (100) with Different Degrees of Crystalline Surface Order. Journal of Electroanalytical Chemistry 269: 175-89

55. Gómez R, Llorca MJ, Feliu JM, Aldaz A. 1992. The behavior of germanium adatoms irreversibly adsorbed on platinum single-crystals. Journal of Electroanalytical Chemistry 340: 349-55

56. Feliu JM, Fernández-Vega A, Aldaz A, Clavilier J. 1988. New observations of a structure sensitive electrochemical-behavior of irreversibly adsorbed arsenic and antimony from acidic solutions on $\mathrm{Pt}(111)$ and $\mathrm{Pt}(100)$ orientations. Journal of Electroanalytical Chemistry 256: 149-63

57. Orts JM, Rodes A, Feliu JM. 1997. Irreversibly adsorbed As at full blockage on Pt(111) electrodes: surface stoichiometry. Journal of Electroanalytical Chemistry 434: 121-27

58. Climent V, Herrero E, Feliu JM. 1998. Electrocatalysis of formic acid and CO oxidation on antimony-modified Pt(111) electrodes. Electrochimica Acta 44: 1403-14

59. Feliu JM, Gómez R, Llorca MJ, Aldaz A. 1993. Electrochemical-behavior of irreversibly adsorbed selenium dosed from solution on $\mathrm{Pt}(\mathrm{h}, \mathrm{k}, \mathrm{l})$ single-crystal electrodes in sulfuric and perchloric-acid media. Surface Science 289: 152-62

60. Feliu JM, Llorca MJ, Gómez R, Aldaz A. 1993. Electrochemical-behavior of irreversibly adsorbed tellurium dosed from solution on $\mathrm{Pt}(\mathrm{h}, \mathrm{k}, \mathrm{l})$ single-crystal electrodes in sulfuric and perchloric-acid media. Surface Science 297: 209-22

61. Climent V, García-Aráez N, Feliu JM. 2008. Clues for the Molecular-Level Understanding of Electrocatalysis on Single-Crystal Platinum Surfaces Modified by p-Block Adatoms. In Fuel Cell Catalysis, pp. 209-44: John Wiley \& Sons, Inc.

62. Solla-Gullón J, Rodríguez P, Herrero E, Aldaz A, Feliu JM. 2008. Surface characterization of platinum electrodes. Physical Chemistry Chemical Physics 10: 1359-73

63. Armand D, Clavilier J. 1987. Quantitative-analysis of the distribution of the hydrogen adsorption states at platinum surfaces. 2. Application to Pt (110), stepped and polyoriented platinum surfaces in sulfuric-acid medium. Journal of Electroanalytical Chemistry 233: 251-65

64. Armand D, Clavilier J. 1987. Quantitative-analysis of the distribution of the hydrogen adsorption states at platinum surfaces.1. Application to Pt (100) in sulfuric-acid medium. Journal of Electroanalytical Chemistry 225: 205-14

65. Vidal-Iglesias FJ, Arán-Ais RM, Solla-Gullon J, Herrero E, Feliu JM. 2012. Electrochemical Characterization of Shape-Controlled Pt Nanoparticles in Different Supporting Electrolytes. ACS Catalysis 2: 901-10

66. J. Solla-Gullón FJV-I, E. Herrero, J. M. Feliu, A. Aldaz. 2013. Electrocatalysis on ShapeControlled Pt Nanoparticles. In Polymer Electrolyte Fuel Cells: Science, Applications, and Challenges, ed. AA Franco, pp. 93-52. Boca Raton, Florida: Pan Stanford Publishing Pte Ltd

67. Martínez-Rodríguez RA, Vidal-Iglesias FJ, Solla-Gullón J, Cabrera CR, Feliu JM. 2014. Synthesis and Electrocatalytic Properties of H2SO4-Induced (100) Pt Nanoparticles Prepared in Water-in-Oil Microemulsion. ChemPhysChem 15: 1997-2001

68. Arán-Ais RM, Vidal-Iglesias FJ, Solla-Gullon J, Herrero E, Feliu JM. 2015. Electrochemical characterization of clean shape-controlled Pt nanoparticles prepared in presence of oleylamine/oleic acid. Electroanalysis (New York) 27: 945-56

69. Martinez-Rodriguez RA, Vidal-Iglesias FJ, Solla-Gullon J, Cabrera CR, Feliu JM. 2016. Electrochemical Characterisation of Platinum Nanoparticles Prepared in a Water-in-Oil 
Microemulsion in the Presence of Different Modifiers and Metal Precursors. Chemelectrochem 3: 1601-08

70. Martínez-Rodríguez RA, Vidal-Iglesias FJ, Solla-Gullon J, Cabrera CR, Feliu JM. 2014. Synthesis of Pt nanoparticles in water-in-oil microemulsion: on the effect of $\mathrm{HCl}$ on their surface structure. Journal of the American Chemical Society 136: 1280-83

71. López-Cudero A, Vidal-Iglesias FJ, Solla-Gullón J, Herrero E, Aldaz A, Feliu JM. 2009. Formic acid electrooxidation on Bi-modified polyoriented and preferential (111) Pt nanoparticles. Physical Chemistry Chemical Physics 11: 416-24

72. Moglianetti M, Solla-Gullon J, Donati P, Pedone D, Debellis D, et al. 2018. Citrate-Coated, Size-Tunable Octahedral Platinum Nanocrystals: A Novel Route for Advanced Electrocatalysts. ACS Applied Materials \& Interfaces 10: 41608-17

73. Grozovski V, Solla-Gullon J, Climent V, Herrero E, Feliu JM. 2010. Formic Acid Oxidation on Shape-Controlled Pt Nanoparticles Studied by Pulsed Voltammetry. Journal of Physical Chemistry C 114: 13802-12

74. Vidal-Iglesias FJ, Solla-Gullón J, Rodríguez P, Herrero E, Montiel V, et al. 2004. Shapedependent electrocatalysis: ammonia oxidation on platinum nanoparticles with preferential (100) surfaces. Electrochemistry Communications 6: 1080-84

75. Figueiredo MC, Vidal-Iglesias FJ, Solla-Gullon J, Climent V, Feliu JM. 2012. Nitrate Reduction on Platinum (111) Surfaces Modified with Bi: Single Crystals and Nanoparticles. Zeitschrift Fur Physikalische Chemie-International Journal of Research in Physical Chemistry \& Chemical Physics 226: 901-17

76. Figueiredo MC, Solla-Gullón J, Vidal-Iglesias FJ, Climent V, Feliu JM. 2013. Nitrate reduction at $\mathrm{Pt}(100)$ single crystals and preferentially oriented nanoparticles in neutral media. Catalysis Today 202: 2-11

77. Duca M, Figueiredo MC, Climent V, Rodriguez P, Feliu JM, Koper MTM. 2011. Selective Catalytic Reduction at Quasi-Perfect Pt(100) Domains: A Universal Low-Temperature Pathway from Nitrite to N2. Journal of the American Chemical Society 133: 10928-39

78. Herrero E, Buller L, Abruna HD. 2001. Underpotential deposition at single crystal surfaces of $\mathrm{Au}, \mathrm{Pt}, \mathrm{Ag}$ and other materials. Chemical Reviews (Washington, DC, United States) 101: 1897-930

79. Hernández J, Solla-Gullón J, Herrero E, Feliu JM, Aldaz A. 2009. In Situ Surface Characterization and Oxygen Reduction Reaction on Shape-Controlled Gold Nanoparticles. Journal of Nanoscience and Nanotechnology 9: 2256-73

80. Hara M, Linke U, Wandlowski T. 2007. Preparation and electrochemical characterization of palladium single crystal electrodes in $0.1 \mathrm{M} \mathrm{H} 2 \mathrm{SO} 4$ and $\mathrm{HClO} 4$ part I. Low-index phases. Electrochimica Acta 52: 5733-48

81. Hoshi N, Kagaya K, Hori Y. 2000. Voltammograms of the single-crystal electrodes of palladium in aqueous sulfuric acid electrolyte: $\mathrm{Pd}(\mathrm{S})-[\mathrm{n}(111) \times(111)]$ and $\mathrm{Pd}(\mathrm{S})-$ [n(100)x(111)]. Journal of Electroanalytical Chemistry 485: 55-60

82. Hoshi N, Kuroda M, Hori Y. 2002. Voltammograms of stepped and kinked stepped surfaces of palladium: $\mathrm{Pd}(\mathrm{S})-[\mathrm{n}(111) \times(100)]$ and $\mathrm{Pd}(\mathrm{S})-[\mathrm{n}(100) \times(110)]$. Journal of Electroanalytical Chemistry 521: 155-60

83. $\mathrm{Xu} \mathrm{QQ}$, Linke U, Bujak R, Wandlowski T. 2009. Preparation and electrochemical characterization of low-index rhodium single crystal electrodes in sulfuric acid. Electrochimica Acta 54: 5509-21

84. Rhee CK, Wasberg M, Zelenay P, Wieckowski A. 1991. Reduction of perchlorate on rhodium and its specificity to surface crystallographic orientation. Catalysis Letters 10: 149-64

85. Zelenay P, Horanyi G, Rhee CK, Wieckowski A. 1991. Voltammetric and radioactive labeling studies of single crystal and polycristaline rhodium electrodes in sulfatecontaining electrolytes. Journal of Electroanalytical Chemistry 300: 499-519 
86. Hunter JD. 2007. Matplotlib: A 2D Graphics Environment. Computing in Science \& Engineering 9: 90-95

87. 1993. CRC Handbook of Chemistry and Physics. London: CRC Press 
Table 1. Dimensions of the unit cell and charge for terrace and step atoms according the hard sphere model for fcc surfaces. Charge values for the basal planes calculated according to metallic diameter of platinum $(d=2.7744 \AA)(87)$

\begin{tabular}{|c|c|c|c|c|c|}
\hline Surface & Area of the unit cell & $\begin{array}{l}\text { Terrace atoms per unit } \\
\text { cell }\end{array}$ & $q_{M L}^{\text {terr }} / \mu \mathrm{C} \mathrm{cm}{ }^{-2}$ & $q_{M L}^{\text {step }} / \mu \mathrm{C} \mathrm{\textrm {cm } ^ { - 2 }}$ & $\cos (\alpha)$ \\
\hline $\operatorname{Pt}(111)$ & $\frac{\sqrt{3}}{2} d^{2}$ & & 240 & & \\
\hline $\begin{array}{l}\mathrm{Pt}(\mathrm{S})[(n-1)(111) \times(110)] \\
\mathrm{Pt}(n n n-2)\end{array}$ & $\frac{\sqrt{3}}{2} d^{2}\left(n-\frac{2}{3}\right)$ & $n-2$ & $q_{P t(111)}-\frac{4}{3} \frac{q_{P t(111)}}{\left(n-\frac{2}{3}\right)}$ & $\frac{q_{P t(111)}}{\left(n-\frac{2}{3}\right)}$ & $\frac{3 n-2}{\sqrt{9 n^{2}-12 n+12}}$ \\
\hline \multirow[t]{2}{*}{$\begin{array}{l}\operatorname{Pt}(\mathrm{S})[n(111) \times(100)] \\
\operatorname{Pt}(n+1 n-1 n-1)\end{array}$} & \multirow[t]{2}{*}{$\frac{\sqrt{3}}{2} d^{2}\left(n-\frac{1}{3}\right)$} & $n-1$ & $q_{P t(111)}-\frac{2}{3} \frac{q_{P t(111)}}{\left(n-\frac{1}{3}\right)}$ & \multirow[t]{2}{*}{$\frac{q_{P t(111)}}{\left(n-\frac{1}{3}\right)}$} & \multirow[t]{2}{*}{$\frac{3 n-1}{\sqrt{9 n^{2}-6 n+9}}$} \\
\hline & & $n-2^{\mathrm{a}}$ & $q_{P t(111)}-\frac{5}{3} \frac{q_{P t(111)}}{\left(n-\frac{1}{3}\right)}$ & & \\
\hline $\mathrm{Pt}(100)$ & $d^{2}$ & & 208 & & \\
\hline \multirow[t]{2}{*}{$\begin{array}{l}\operatorname{Pt}(S)[n(100) \times(111)] \\
\operatorname{Pt}(2 n-1111)\end{array}$} & \multirow[t]{2}{*}{$d^{2}\left(n-\frac{1}{2}\right)$} & $n-2$ & $q_{P t(100)}-\frac{3}{2} \frac{q_{P t(100)}}{\left(n-\frac{1}{2}\right)}$ & \multirow[t]{2}{*}{$\frac{q_{P t(100)}}{\left(n-\frac{1}{2}\right)}$} & \multirow[t]{2}{*}{$\frac{2 n-1}{\sqrt{4 n^{2}-4 n+3}}$} \\
\hline & & $n-1 / 2^{\mathrm{b}}$ & $q_{P t(100)}-\frac{q_{P t(100)}}{\left(n-\frac{1}{2}\right)}$ & & \\
\hline $\mathrm{Pt}(110)$ & $\sqrt{2} d^{2}$ & & 147 & & \\
\hline
\end{tabular}

${ }^{a}$ While the natural separation of atomic sites in the Pt(S) $[n(111) \times(100)]$ stepped surface would be 1 step atom and $n-1$ terrace atoms per unit cell, the actual separation depends on the reaction under scope. For the bismuth covered surface considered below, only $n-2$ sites are available per unit cell for bismuth adsorption.

${ }^{\mathrm{b}}$ For the $\mathrm{Pt}(\mathrm{S})[n(100) \times(111)]$ stepped surfaces, the categorization of surface sites based on hydrogen adsorption would be 1 step site, 1 edge site and $n-2$ terrace sites. However, for the germanium covered surface, it has been shown that $n-1 / 2$ surface sites per unit cell are available for germanium adsorption. 


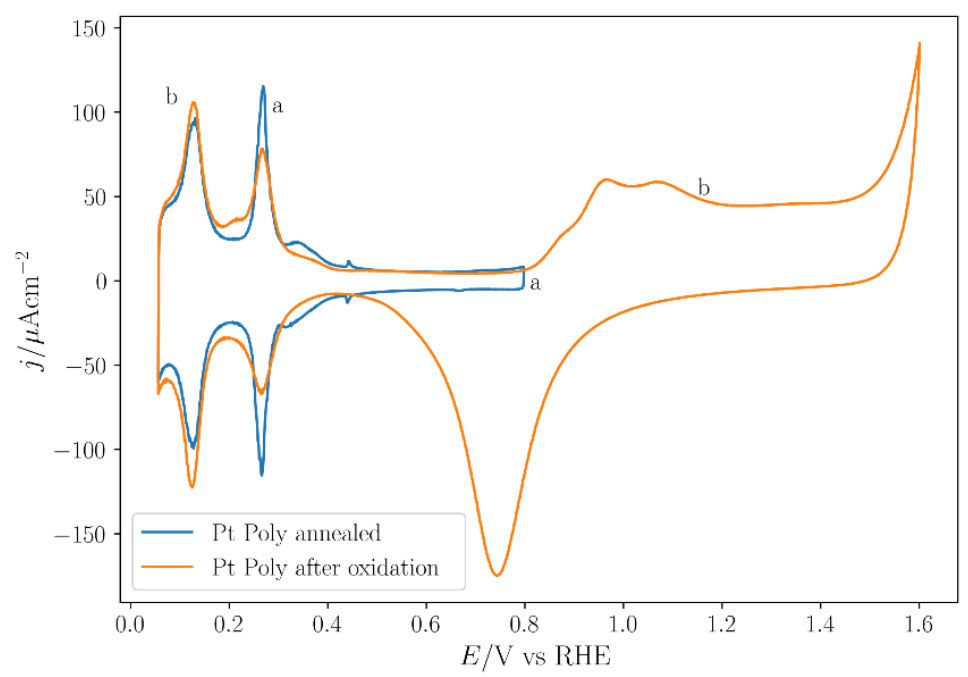

Figure 1: Cyclic voltammograms for a polyoriented spherical platinum electrode in $0.5 \mathrm{M} \mathrm{H}_{2} \mathrm{SO}_{4}$ after flame annealing, before (a) and after (b) several cycles of oxidation and reduction, scan rate $=50 \mathrm{mV} / \mathrm{s}$.

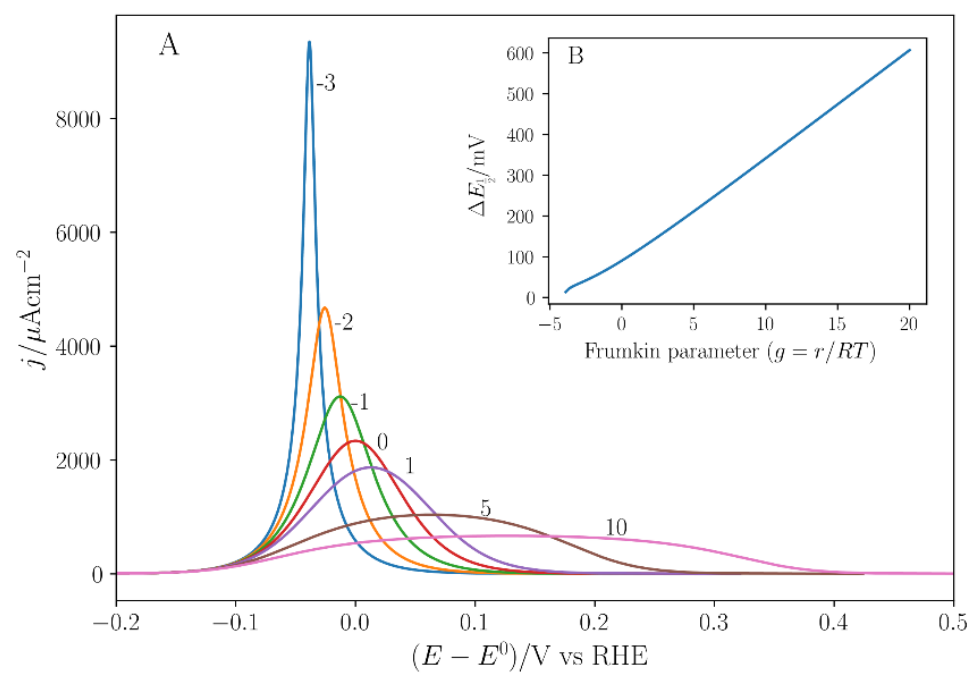

Figure 2: A) Calculated cyclic voltammograms (positive sweep) for an electrosorption process of an anion with $q_{M L}=240 \mu \mathrm{Ccm}^{-2}, v=1 \mathrm{Vs}^{-1}, T=298 \mathrm{~K}$ and different values of the lateral interaction parameter $g=r / R T$, as indicated in the figure. B) variation of the width of the voltammetric peak at half height with the lateral interaction parameter. 


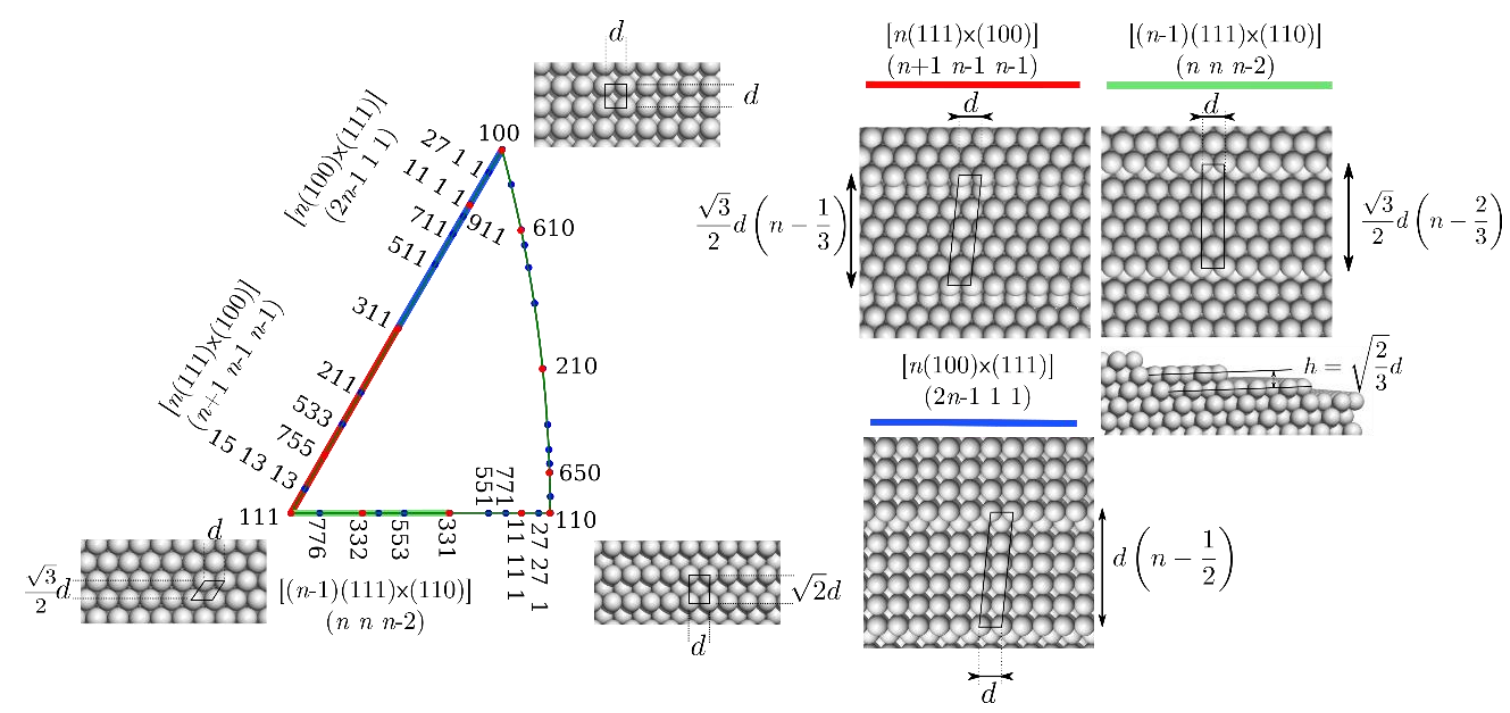

Figure 3: Stereographic triangle for a face centred cubic crystal with the hard sphere model of some selected surfaces, indicating the main dimensions of the unit cell.
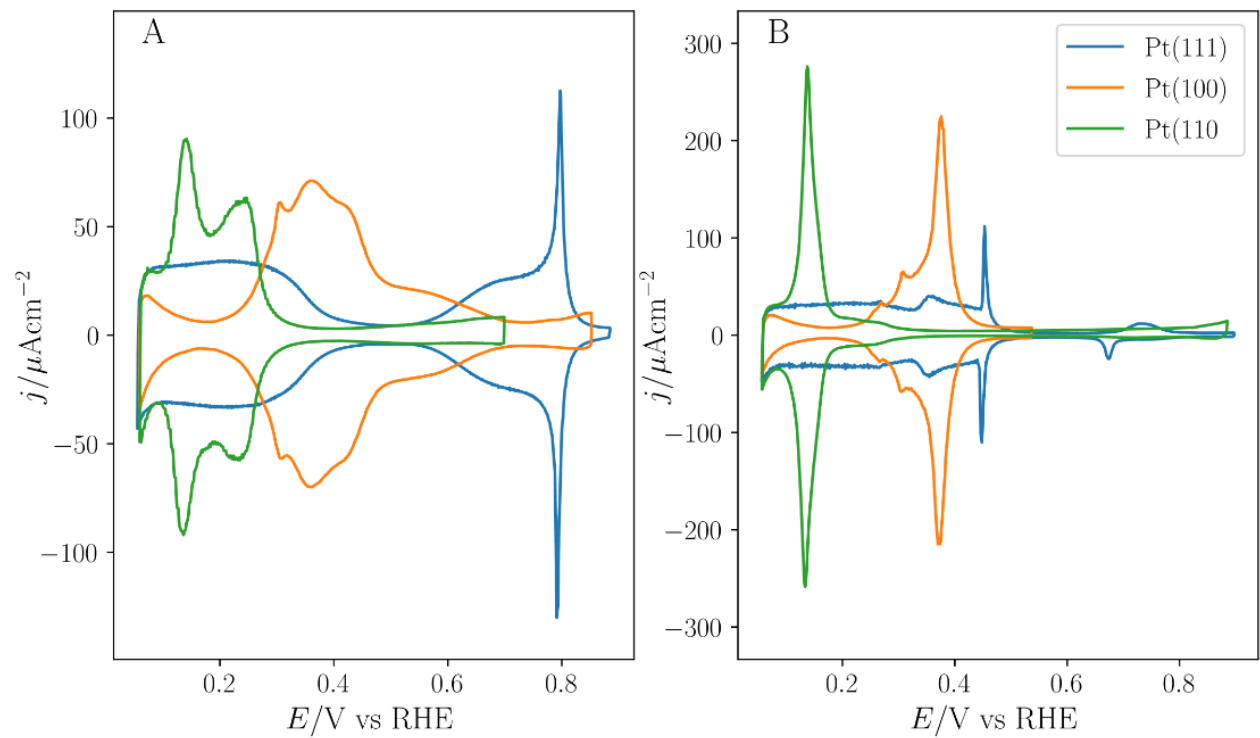

Figure 4: Cyclic voltammograms for the three basal planes of platinum in different supporting electrolytes: A) $0.1 \mathrm{M} \mathrm{HClO}_{4}$; B) $0.5 \mathrm{M} \mathrm{H}_{2} \mathrm{SO}_{4}$. Scan rate $=50 \mathrm{mV} / \mathrm{s}$ 

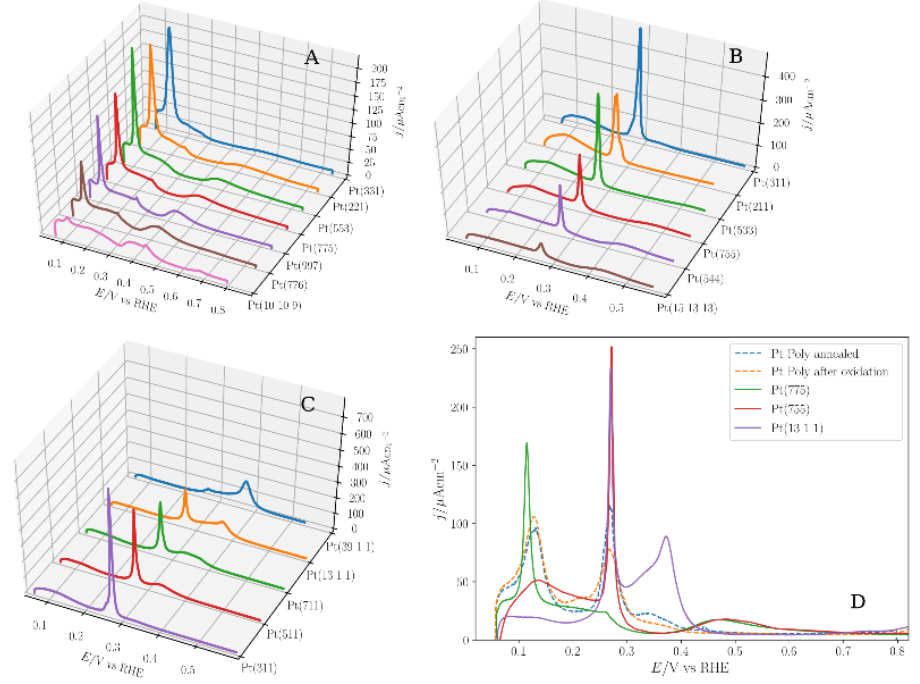

Figure 5: cyclic voltammograms of several $\mathrm{Pt}$ stepped surfaces in $0.5 \mathrm{M} \mathrm{H}_{2} \mathrm{SO}_{4}$. A) $\mathrm{Pt}(\mathrm{S})[\mathrm{n}(111) \times(110)] ; \mathrm{B}) \mathrm{Pt}(\mathrm{S})[\mathrm{n}(111) \times(100) ; \mathrm{C}) \mathrm{Pt}(\mathrm{S})[\mathrm{n}(100) \times(111)] ; \mathrm{D})$ comparison of the same voltammograms of figure 1 for a polyoriented electrode with the voltammetric profile of some selected stepped surfaces. Scan rate: $50 \mathrm{mV} / \mathrm{s}$
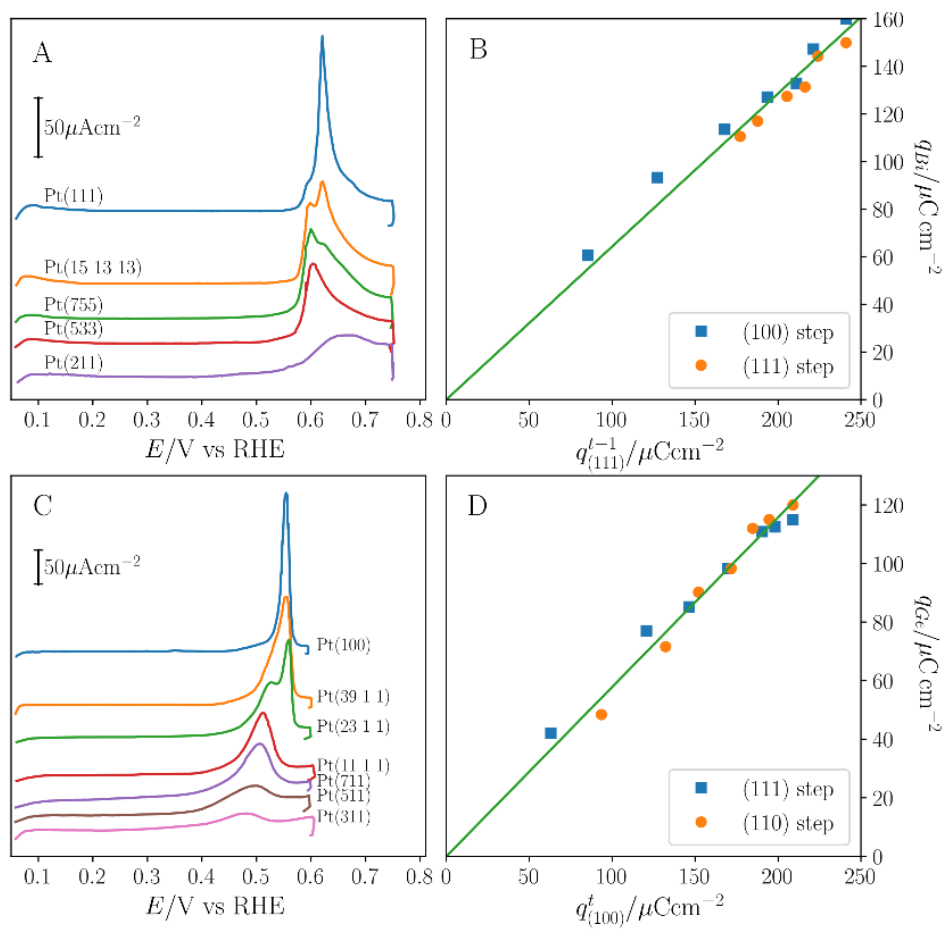

Figure 6: Voltammetric response of several stepped surfaces covered with adatoms A) Bi on $\mathrm{Pt}(\mathrm{S})[\mathrm{n}(111) \times(100)]$ C) Ge on Pt(S) $[n(100) \times(111)]$. B and D) Plot of the charge of the adatom peak as a function of the terrace charge, according to the hard sphere model (Table 1): $\mathrm{B}$ ) Bi on (111) terraces and D) Ge on (100) terraces. 

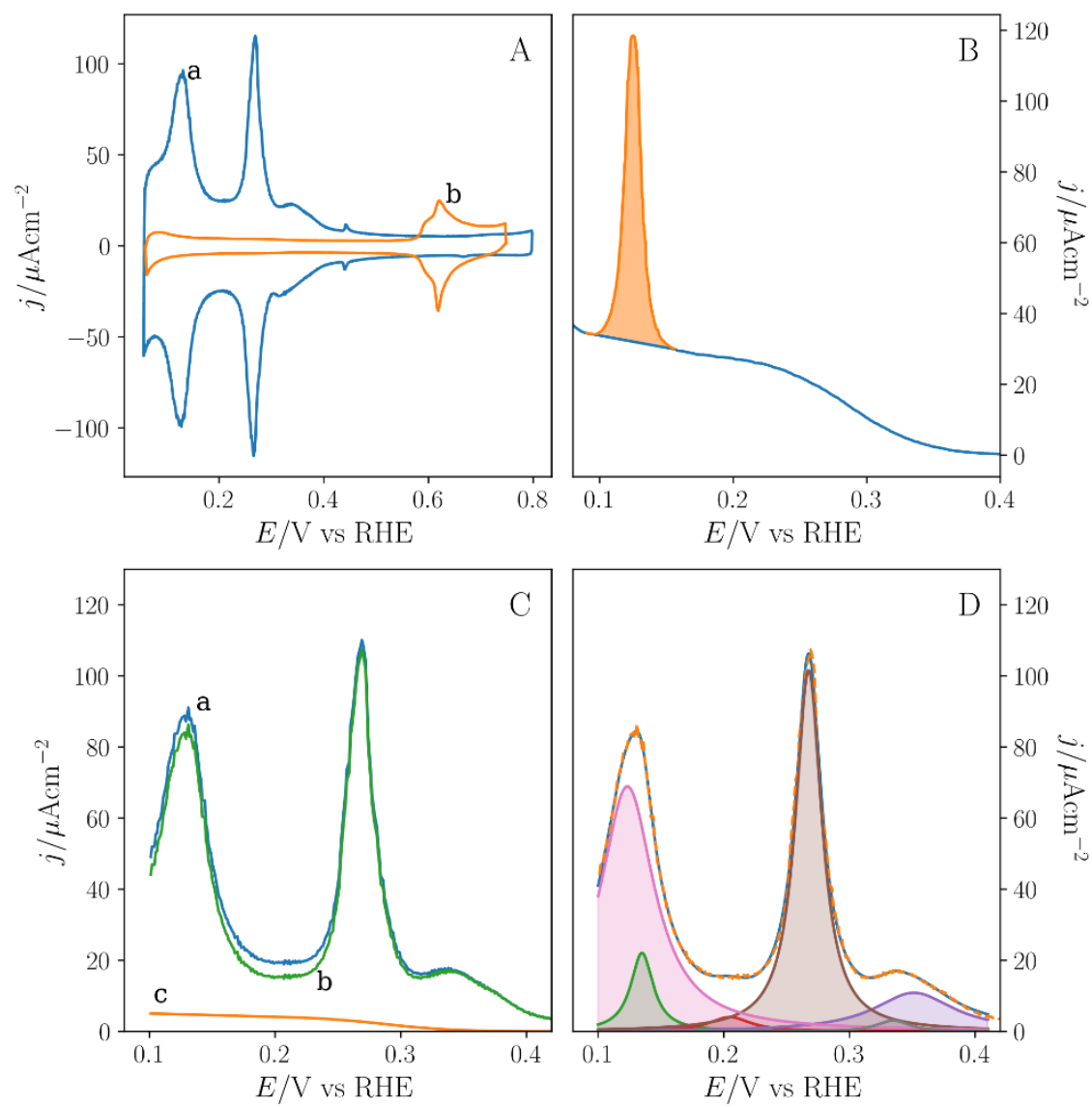

Figure 7: Different steps for the mathematical separation of the different contributions in the hydrogen region of a polycrystalline platinum surface. A) the electrode is covered with $\mathrm{Bi}$ to determine the amount of (111) domains. a) initial voltammogram and b) covered with Bi. B) The terrace and step contributions from a voltammogram of a $\mathrm{Pt}(554)$ electrode are separated and the terrace contribution is used to subtract the fraction of (111) sites from the polycrystalline material. C) Initial (a) and corrected (b) voltammogram, together with the terrace from Pt(544) scaled curve (c) used for subtraction of (111) sites. D) Fit of six Lorentzian peaks (solid line) to the corrected voltammetric current (dashed line) and separation into different contributions. $0.5 \mathrm{M} \mathrm{H}_{2} \mathrm{SO}_{4}$ (except the $\mathrm{CV}$ for $\mathrm{Pt}(554)$ that is recorded in $0.1 \mathrm{M} \mathrm{HClO}_{4}$ ). Scan rate= $50 \mathrm{mV} / \mathrm{s}$ 

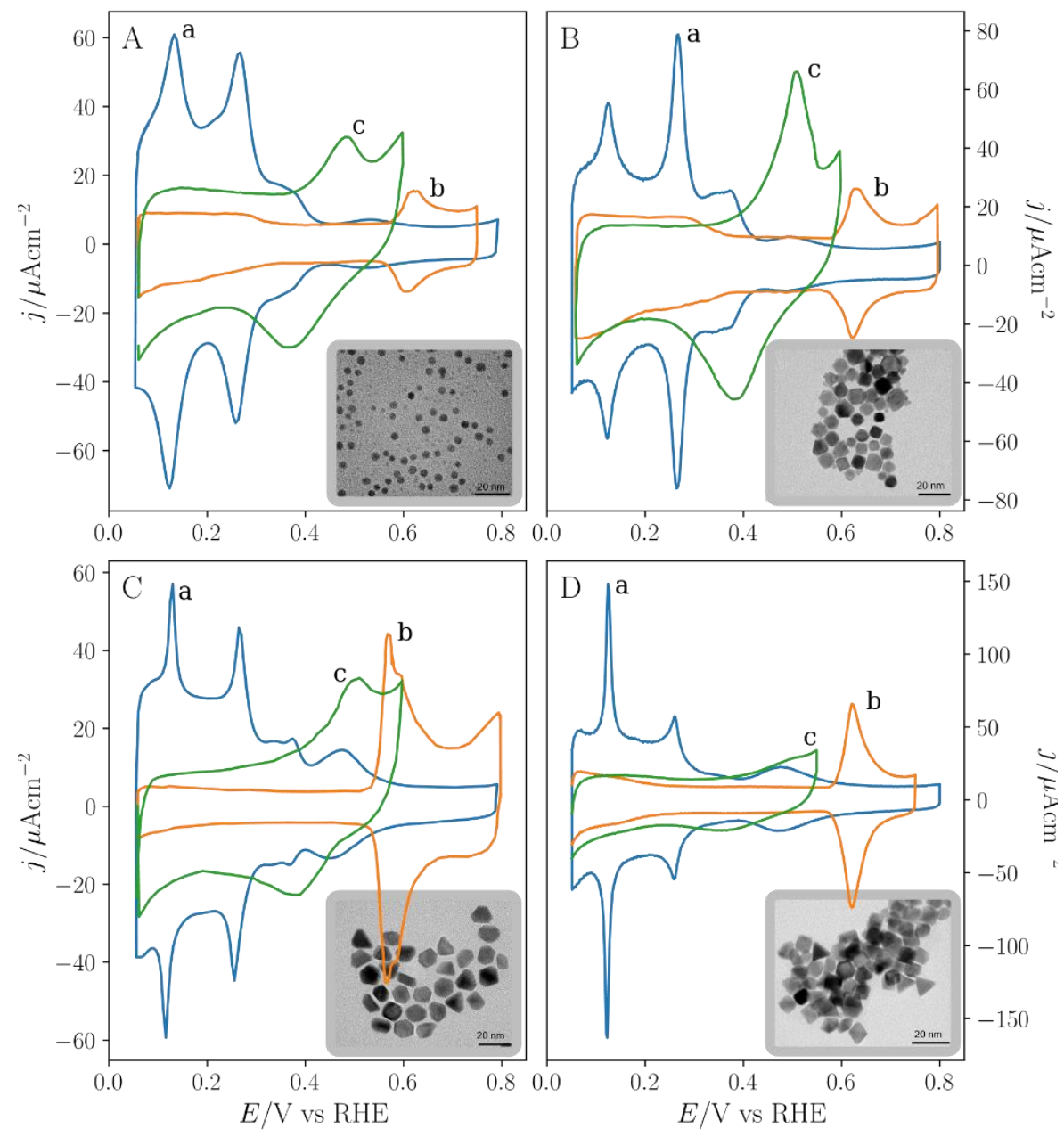

Figure 8: Cyclic voltammograms obtained with platinum nanoparticles with different preferential shapes. A) spherical nanoparticles synthesised with the water in oil microemulsion method. B) cubic nanoparticles obtained with the polyacrylate method. C) Truncated tetrahedral and octahedral nanoparticle obtained with the polyacrylate method. D) Tetrahedral nanoparticles obtained with the polyacrylate method. a) unmodified surface; b) Bismuth modified surface; c) Germanium modified surface. $0.5 \mathrm{M} \mathrm{H}_{2} \mathrm{SO}_{4}$. Scan rate $=50 \mathrm{mV} / \mathrm{s}$ 